\title{
Stories of Policing: The Role of Storytelling in Police Students' Sensemaking of Early Work-Based Experiences
}

\author{
Oscar Rantatalo $^{1}$ (D) Staffan Karp ${ }^{2}$
}

Received: 19 December 2016 / Accepted: 3 July 2017 /

Published online: 7 July 2017

(C) The Author(s) 2017. This article is an open access publication

\begin{abstract}
Storytelling has been shown to play a key role in transferring work experience from more experienced towards novices in a number of vocational educational practices, however previous studies have not to the same extent dealt with the role of students' own storytelling practices for sensemaking of work experience. This study set out to examine police students' storytelling of their first occupational experiences from a sensemaking perspective, with an analysis drawing on the concepts of enactment, selection, and retention. The study is based on participant observations of field training follow up sessions' in the context of police education. Findings indicated that student storytelling of work experience tended to be geared towards action, extremeness and the telling of 'war stories'. Furthermore, these type of stories functioned to enable student identification, self-enhancement and emotion management. These findings contribute to our current understanding of how students engage in sensemaking of work-based experiences and in extension how knowledge integration and learning from work placements can be structured pedagogically.
\end{abstract}

Keywords Storytelling $\cdot$ Policing $\cdot$ Sensemaking $\cdot$ Knowledge integration

A longstanding theme in research on vocational education and training has been how work-based experiences for students can be integrated with learning in vocational and higher education programmes (Aarkrog 2005; Sappa and Aprea 2014; Stenström and Tynjälä 2009; Tynjälä 2013). As stated by Billett et al. (2013) and Billett (2009, 2014), a central challenge for educational institutions that provide work-based student

Oscar Rantatalo

oscar.rantatalo@umu.se

1 Police Education Unit, Umeå University, 90187 Umeå, Sweden

2 Department of Education, Umeå University, Umeå, Sweden 
placements (i.e., practicums) is how experience can be integrated across settings and specifically how opportunities for students to articulate and share experience with each other can be pedagogically organised. A key issue in knowledge integration is ensuring that students have opportunities to retrospectively interpret, share and make sense of work experiences acquired through various forms of practicums and work placements (Bijlsma et al. 2016). Arguably, increased knowledge of how students make sense of early work experience could be of importance for the development of integrative pedagogical approaches in which the connectivity of different modes of knowledge is central (Tynjälä 2008).

We address this issue through an empirical study that explores police students' narrative sensemaking of occupational experience in the context of police training. In detail, the study examines the role of police students' storytelling, specifically the telling of 'war stories' (cf. Van Maanen 1973, 1975), in students' endeavours to make sense of work experiences acquired through work placements. Drawing on a sensemaking framework originally developed by organizational theorist Karl Weick (1995), the study takes a student-centred approach to examine how work experiences are retrospectively made sense of by students interacting in the educational context. This is done in order to facilitate a discussion about how storytelling might function as a process of knowledge integration in occupational education after activities such as work placements.

Theoretically, the current study examines how storytelling may entail a practice of narrative sensemaking. The role of stories and narratives (these terms are used interchangeably in the present study) has been a reoccurring subject in educational research in general (Clandinin and Connelly 2000; Connelly and Clandinin 1990) as well as in research on vocational education (Tyson 2016) and in workplace settings (Boud et al. 2009). As stated by Tyson (2016), narratives are powerful at expressing practical knowledge, as they can facilitate vocational 'bildung', which the author defines as a form of occupation-specific field knowledge. Similarly, Worth (2008 p. 42) discusses how storytelling functions as an important edifying process by which subjects order experience and make 'coherent sense out of seemingly unrelated sequences of events'. In accordance with these findings, research within the police context has highlighted how narratives are an important vehicle for learning in police education (McNulty 1994; Shearing and Ericson 1991). For example, Van Maanen's (1973, 1975) seminal works on police socialization showed how the telling of 'war stories' by police instructors during training transfers experiential knowledge about police departmental history as well as the craft of policing. Van Maanen (1973) described war stories as succinct stories that by analogy demonstrate, explain or clarify occupation-specific lessons. Other works that exemplify the connection between storytelling and learning include Ford (2003), who suggests that stories and parables told in the context of police training transmit values and cultural beliefs from more-experienced officers to students, and Conti (2011) and McNulty (1994) who discuss how storytelling functions as an informal curriculum and as 'previews' of practice in police training.

These studies have convincingly shown how storytelling and narrative are important vehicles for learning occupational and practical knowledge (Smith et al. 2014; Van Hulst 2013; Waddington 1999). However, a shortcoming in the literature on police storytelling is that the bulk of research either describes storytelling practices outside police educational contexts (see Van Hulst 2013) or in terms of a 'top-down' 
unidirectional transfer of knowledge from senior officers to newcomers (Chappell and Lanza-kaduce 2009; Ford 2003). With a predominant focus on how stories transmit meaning from more- to less-experienced practitioners, a currently overlooked aspect in the literature is what role the voice and active engagement of students as storytellers themselves plays in their sensemaking of work-based experiences. Arguably, research that targets what role storytelling has for police students' sensemaking of policing could provide valuable insights into how knowledge integration in the educational context can be facilitated.

\section{Aim}

Building on the above-presented background, the aim of the current study is to examine police students' narrative sensemaking of occupational experience in the context of police training. Empirically, the question we seek to answer is what role students' storytelling practices have for sharing and making sense of early occupational experiences. Based on the empirical examination, our study contributes to narrative approaches to educational research and, more specifically, research on how stories function to organize students' experiences in educational contexts (Clandinin and Connelly, Connelly and Clandinin 1990; Clandinin and Connelly 2000; Worth 2008). Furthermore, the empirical study contributes in-depth knowledge on students' sensemaking of work experience through storytelling practices. As such, the study describes an example of activities aimed at knowledge integration wherein work-based experience retrospectively is made sense of by students in their educational context. As suggested above, increased knowledge on how students engage in sensemaking of work-based experiences is important, as it has implications for how practice-based models of learning can be ordered and organized pedagogically (Billett 2009).

\section{Narrative Sensemaking}

A variety of studies on education and work have researched sensemaking processes. Examples include studies of undergraduate experiences of work placements (Walmsley et al. 2006), learning in everyday work practice (Avby 2015), and knowledge integration in vocational education contexts (Bijlsma et al. 2016). The sensemaking concept applied in this study draws on the work of organizational psychologist Karl Weick (1995). From this perspective, sensemaking refers to "those processes by which people seek plausibly to understand ambiguous equivocal or confusing issues or events" (Brown et al. 2015, p. 266; Weick 1995). Weick's sensemaking framework is often referred to as an ESR model of sensemaking, which describes how meaning is attributed to experience in three broad steps: Enactment, Selection and Retention (Weick et al. 2005; Brown et al. 2015). Sensemaking takes its starting point in enactment, as it is through interactions in the world that subjects engage with various phenomena. This view has similarities with the theory of transactional constructivism as described, for instance, by Dewey (1985). In order to be made sense of, an individual's engagement with the environment needs meaning to be attributed to it. From a sensemaking perspective, this takes place through selection, wherein activities are retrospectively put into frames of reference, given explanations and thus become categorized. Finally, retention refers to the process by which meaning is cognitively and 
collectively retained, for instance, as narratives or common knowledge that connects to past experiences and that can be used as a guide for further action (Weick et al. 2005).

In the ESR model of sensemaking, language and narration has been described as central for how people make sense (Weick 1995). In enactment and selection, verbal and written language is a central mean by which the social world is structured and temporally stabilized. In formulating storylines, courses of events are given temporality and culturally saturated meanings for both the speaker and for others as certain interpretations are selected over others (Maclean et al. 2011). Thus, storytelling is central to both enactment and selection because stories can be viewed as a 'currency' of sensemaking that fixes meaning and invites (or allows) others to build on them (Boje 1995). In this regard, narration can be conceptualized as an activity that allows individuals to share experiences with others and make inferences about experiences, unfolding events and uncertain situations. Likewise, a story can be defined as an "oral or written performance involving two or more people interpreting past or anticipated experience" (Boje 1995 p. 1000).

In addition to being essential to enactment and selection, narratives can also be said to fill a retaining function, as accounts of events also transmit cultural meaning in a proactive way (Brown et al. 2008). Through the production of narratives, sensemaking theory posits that individuals frame experiences in terms of plausible explanations (Maitlis and Christianson 2014). As such, stories are often described as the material result of sensemaking, as individuals produce accounts of equivocal situations and represent phenomena in the social world. However, as stated by Weick (1995), the notion that storytelling is representational does not mean that stories are representative of actual events in the sense that they are complete or "true". Rather, narrative sensemaking is based on the notion of plausibility rather than accuracy. Because storytelling retains knowledge, stories also function as triggers for future sensemaking processes. This means that individuals draw on discourse and previously established meaning in productive ways to make sense of new events (Maitlis and Christianson 2014). Dominant narratives may have "sensegiving" features that channel meaning proactively (Gioia and Chittipeddi 1991; Lawrence and Maitlis (2007).

In the present study, an ESR model of narrative sensemaking is used to analyse students' storytelling practices to capture how newcomers to the police community retrospectively categorize and share their work-based experiences in the educational context. Storytelling practice is thus the empirical phenomenon under examination, whilst an ESR framework of narrative sensemaking is the lens by which this phenomenon is studied.

\section{Methods}

The background to the study reported here is an ongoing ethnographic research project targeting Swedish police training (Rantatalo and Karp 2016). Participant observations and interviews in the project indicated that students' storytelling was a central practice within police education. This initial observation raised the question of how work-based experiences were made sense of through students' storytelling with peers. With this as a starting point, field work narrowed in on settings that illuminate student storytelling within the context of police education. In the vocabulary of Hammersley and Atkinson 
(2007 p. 32), the research reported in this study thus focuses upon an 'ethnographic case' (a phenomenon studied from a particular perspective) in an empirical setting where both the case and the setting gradually developed from insights drawn in a wider inductive and 'loosely designed' research project (Miles et al. 2014 p.19).

\section{Sampling and Participants}

The sampling for this study was purposeful and directed at police students' occasions for storytelling of work experience in follow-up sessions after work placements. Work placements (in the police training literature, referred to as field observations, cf. Chan 2001) in Swedish police education are regularly conducted during the second and third terms of education. At placements, students work regular shifts with senior police officers on active duty. Thereby, the students are exposed to the everyday issues and experiences policing entails. After completing placements, students are scheduled for follow-up sessions conducted at the academy as an opportunity to discuss work-based experiences relatively freely and open-endedly with each other in small groups and with a police instructor present as a facilitator. These sessions showcase many similarities with police debriefings.

The first and second authors (Authors 1 and 2 in Table 1) conducted participant observations of twelve two-hour follow-up sessions with 4-7 students in each session. A total of 66 students from two student cohorts (i.e., two classes) were observed in the sessions, of which $44 \%(n=29)$ were female and 56\% $(n=37)$ were male (in total, the population of police students in Sweden is approximately 30-35\% female and 65-70\% male, depending on admission year, SOU 2016). Four observations were conducted during fall 2015 (cohort 1) and eight during spring 2016 (cohort 2). This distribution was based on the schedule for work placements and follow-up sessions. For an overview of the primary data collection, see Table 1.

Table 1 Details on observations and participants

\begin{tabular}{lll}
\hline Time & Observation & Student group \\
\hline fall 15 & Follow-up session Author $12 \mathrm{~h}$ & $3 \mathrm{~m}, 3 \mathrm{f}$ \\
fall 15 & Follow-up session Author $12 \mathrm{~h}$ & $2 \mathrm{~m}, 2 \mathrm{f}$ \\
fall 15 & Follow-up session Author $12 \mathrm{~h}$ & $3 \mathrm{~m}, 2 \mathrm{f}$ \\
fall 15 & Follow-up session Author $22 \mathrm{~h}$ & $3 \mathrm{~m}, 3 \mathrm{f}$ \\
spring 16 & Follow-up session Author $12 \mathrm{~h}$ & $4 \mathrm{~m}, 2 \mathrm{f}$ \\
spring 16 & Follow-up session Author $12 \mathrm{~h}$ & $4 \mathrm{~m}, 2 \mathrm{f}$ \\
spring 16 & Follow-up session Author $12 \mathrm{~h}$ & $2 \mathrm{~m}, 3 \mathrm{f}$ \\
spring 16 & Follow-up session Author $12 \mathrm{~h}$ & $4 \mathrm{~m}, 2 \mathrm{f}$ \\
spring 16 & Follow-up session Author $12 \mathrm{~h}$ & $4 \mathrm{~m}, 2 \mathrm{f}$ \\
spring 16 & Follow-up session Author $22 \mathrm{~h}$ & $2 \mathrm{~m}, 2 \mathrm{f}$ \\
spring 16 & Follow-up session Author $22 \mathrm{~h}$ & $3 \mathrm{~m}, 2 \mathrm{f}$ \\
spring 16 & Follow-up session Author $22 \mathrm{~h}$ & $3 \mathrm{~m}, 4 \mathrm{f}$ \\
Total = 12 & Author $1=8$, Author $2=4$ & $n=66(\mathrm{f}=29, \mathrm{~m}=37)$ \\
\hline
\end{tabular}

$\mathrm{m}=$ male, $\mathrm{f}=$ female 


\section{Data Sources}

The primary data source in the study is descriptions of sessions recorded through observation field notes and observation protocols. The field notes focused on openly describing the practices of storytelling and on capturing the features and elements of stories that were shared by students (e.g., focusing on describing plots, domains of policing). Initially, the idea was to collect and arrange individual stories of policing in relation to each other. However, initial observations indicated that storytelling was a practice characterised by plurivocity and that a manual separation of stories into separate entities would reduce interpretability and be less receptive towards the enactment dimension of storytelling sessions. The field notes thus focused on describing stories as they were told in an intertwined manner, with features such as overlaps, questions, and interruptions noted as they occurred. Storytelling practices and story content regularly alternated, and field notes could thus shift between describing stories and describing how stories were enacted.

Short informal field interviews with instructors and students were conducted in connection with all observations. With rooting in an ongoing ethnographic project, the authors had prior understandings of the context under study and had previously established entry-level access and social access (i.e., "rapport") with the student groups (Carmel 2011; Punch 1986), which facilitated the collection of spontaneous informant accounts through field interviews. Field interviews were conducted on-site directly before or after follow-up sessions (for example, during breaks and lunch) and revolved around evolving themes pertaining to the observed sessions or questions raised by the observer regarding interpretations of sessions. In this way, the field interviews partly served the purpose of respondent validation of observer interpretations (Lincoln and Guba 1985). While the merits of such 'member checks' has been a subject of discussion (Torrance 2012), the method served to provide the authors with clarifications regarding students' use of concepts and their perspectives and outlooks in relation to storytelling.

In addition to the 'open' field notes described above, an observation protocol (originally developed for the ethnographic project this study developed from) was filled in by the observers directly after every conducted observation. This protocol was designed to register descriptive data of the observation (date, location, number of participants) as well as structural, pedagogical and social dimensions of the observation. Structural indicators focused on assessing aspects related to the time and space of the observation, such as time frames and spatial arrangements. Pedagogical indicators were directed at assessing how sessions were organized to promote learning. Finally, social indications focused on how subjects interacted in terms of, for example, critical opinion sharing or collective learning-centred discussions. The observers made short notes in relation to each indicator in order to construct an overview of the observed session and to assess and compare observations with each other.

\section{Data Analysis}

To aid analysis, the software Nvivo 10 (http://www.qsrinternational.com) was used. Following recommendations from Miles et al. (2014), the data analysis was informed by a conceptual framework specifying central constructs. In the specific case, 
sensemaking entailed such a framework, with the concepts enactment, selection and retention directing the data analysis.

First, through the concept of enactment, practices of storytelling recorded through field notes and observation protocols were reviewed and compared based on students' activities during sessions. Examples could be how turn-taking was enacted or what role probing questions had in these sessions. In other words, this cycle of analysis was centred on the social practice of storytelling and how it provided a framework for the sharing of work-based experiences.

Second, the internal structure of stories was analysed as an indication of how selection was made from experience. To practically analyse the selection step of sensemaking, we conducted cycles of first and second order coding (Miles et al. 2014). First, we coded the textual narratives that were collected through observations based on what these were about. More specifically, we coded what occupational domains (contexts, times, spaces, spatial boundaries), subjects and social relations the stories described. After coding narratives individually (what we term first order), these were categorized and assessed in relation to each other (second order) in order to identify common patterns.

Third, to understand how meaning and knowledge was retained through stories, the analysis targeted the representational role of stories. To analyse retention processes, we used the textual narratives and categorized themes in stories based on what we defined as an underlying or 'latent' level that described the meanings and messages of stories. For example, a story told by a student about a violent fight amongst drug addicts could, on a manifest level, be vividly descriptive of injuries and blood, but on an underlying level, it could revolve around the difficulties a new police officer faces in distinguishing between aggressor and victim in an uncertain situation. To make interpretations about an underlying level of stories, connections were made between what stories were about (the internal structure analysed through selection), how stories were told and received (the enactment dimension of sensemaking), and how students interpreted the stories (conveyed through, for instance, field interviews). The data analysis is summarised in Table 2 .

Table 2 Analytical Steps: Procedures and Outcomes

\begin{tabular}{|c|c|c|c|}
\hline & Enactment & Selection & Retention \\
\hline Procedure & $\begin{array}{l}\text { Analysing storytelling practices } \\
\text { based on } \\
\text { - How stories are told in situ } \\
\text { - Who is involved in storytelling } \\
\text { and how are they involved } \\
\text { - How the contextual setting is } \\
\text { structured (observation } \\
\text { protocol) }\end{array}$ & $\begin{array}{l}\text { Analysing internal structure } \\
\text { of narratives } \\
\text { - Subjects and their social } \\
\text { relations } \\
\text { - Occupational domains } \\
\text { (contexts, times, places, } \\
\text { spatial boundaries) } \\
\text { - Identifying patterns across } \\
\text { narratives }\end{array}$ & $\begin{array}{l}\text { Analysing messages of } \\
\text { narratives and knowledge } \\
\text { conveyed through } \\
\text { storytelling } \\
\text { - What do stories represent } \\
\text { - What are the key messages } \\
\text { of the stories } \\
\text { - What kinds of common sense } \\
\text { 'knowledge' do stories } \\
\text { convey }\end{array}$ \\
\hline Outcome & $\begin{array}{l}\text { Indication of how storytelling } \\
\text { unfolds in practice. } \\
\text { (i.e., how storytelling is } \\
\text { constrained or prompted) }\end{array}$ & $\begin{array}{l}\text { Data structure highlighting } \\
\text { what occupational } \\
\text { narratives were about. }\end{array}$ & $\begin{array}{l}\text { Data structure showcasing } \\
\text { underlying 'latent' themes } \\
\text { of stories. }\end{array}$ \\
\hline
\end{tabular}


Although the enactment, selection and retention processes are depicted as separate in the model described in Table 1, it should be noted that this separation of enactment selection and retention is for analytical purposes.

\section{Findings}

Based on the three-step analysis described above, we now describe how the activities of telling and retelling of stories function as a practice of sensemaking in which police students articulate their first occupational experiences. Findings are presented in the following three sections, which outline storytelling practices, selection of stories and how knowledge retention was achieved through storytelling. Themes within the empirical material are presented in overview as well as in detail through exemplifying field note extracts.

\section{Storytelling Practices}

The students frequently expressed that the follow-up sessions were important and that they appreciated the educational events. The storytelling within these sessions was often of a collective nature, prompted by questions from the facilitator and by peers. The sessions were open-ended, characterized by improvisation and were more disorganized than initially expected. Stories about occupational realities were often not in finished form when they were first voiced. Rather, the activity of articulating one's understandings and experiences of field work was of an interactive nature, without clear beginnings, ends, or plot twists. Narratives were often structured by an external criterion such as time (describing day-to-day experiences), theme (e.g., describing a number of dispatch calls of a particular sort) or by association with a previous story or statement. The primary strategy for storytelling during the sessions was characterized by ongoing composition by the storytellers, which was regularly supported and facilitated by peers and by the instructor who often triggered stories through probing questions. These questions were important in the light of a common and somewhat paradoxical occurrence, which was that students often began their stories by assuring peers and the instructor that they did not have anything to tell, a statement that often was followed by quite severe, serious or sometimes incredible accounts of occupational police practice. One example from the field notes that highlights the importance of triggering questions for the facilitation of storytelling was when a female student (D) was summarizing her field experiences when prompted to do so by the instructor (I.N):

$\mathrm{D}$ seems to have some trouble knowing where to begin. She says that she spent some time on patrol, that she followed investigators around for a few days and did a little bit of everything such as reporting and interrogations. I.N asks some questions to assist D: "Did you mainly work dayshifts, nights...?" This question seems to resonate with D, and she starts talking about how she had done night shifts during the weekend. I.N asks if something "stood out" during these shifts. In response, D starts recounting an upsetting episode that she says she thought a lot about afterwards. It was about a disturbance in a nightclub where a guest had been severely beaten up by bouncers who covered for each other in their stories. D says that there were two witnesses at the scene who had seen the doormen beating and kicking the man and throwing him from a 
loading bay. The patrol took reports and called for an ambulance. D says that she was glad that they had witnesses, as this should make it a clear-cut case. However, upon discussing it with her more experienced colleagues, she learned that it would probably not lead to convictions due to the bouncers' backing up each other's stories.

Upon recounting this, D elicits recognition and frustration in the room. Several others fill in and describe similar experiences of injustice, such as bouncers who had been pointed out by patrol officers as infamous for being involved in beatings. The discussion starts to revolve around the paradoxical fact that in the story, the bouncers were the ones calling upon police as victims of violence, and in that capacity, they were plaintiffs. However, D's story exemplifies how they also were the ones causing distress.

This episode was recounted by a student who initially had a hard time sorting out her impressions and selecting what to address in the session, especially she had a hard time sorting out what happened on which day. However, after some coaxing from others in the room (especially the instructor I.N), she recounted a serious and stressful account that brought recognition and sparked dialogue amongst her peers. The episode represents several defining aspects of how retrospective storytelling arranged the meaning of occupational experiences. First, the story exemplifies a constructed narrative that moves from a generic description of work placement and night shift work to a vivid example of injustice and power abuse. Important to note is that this example of narrative sensemaking was a collective achievement: The story was triggered by probing questions and dialogue, and the recognition of the story's additional meaning was a shared experience of feelings of being upset. In the example, the instructor played a role as a dialogic counterpart to the student and as the one who initially gave the word to her and, as such, sparked the conversation, however, the instructor also held back after D started talking, giving her space to elaborate on her story.

\section{Selection of Stories}

Based on the second step of our analytical approach, we analysed our empirical material in search of themes describing which subjects, social relations and domains of policing recurred in police students' stories. In this regard, three aspects stood out. When selecting subjects and social relations from experience, students tended to discuss colleagues (good guys) and criminals (bad guys). Furthermore, when contextualizing stories, a common tendency was to focus upon extreme situations, and when discussing policing, stories that reinforced notions of policing as actionable occurred frequently. These aspects are detailed below.

Regarding subjects and social relations, normative narratives about colleagues within the police community were the most common theme. These stories tended to depict heroic and desirable behaviours of colleagues or, conversely, less-desirable behaviours. The stories were, for example, about police who were good at "reading" situations, shifting tempo, addressing citizens in respectful ways, having good attitudes in general or being good at specific policing tasks (such as incident management or K9 tracking). Conversely, stories about unwanted behaviour from colleagues regularly fell into two categories: stories about worn-out, lazy, tired police or about overly macho and unnecessarily harsh police officers who had made bad impressions on students. Besides colleagues, students also referred in their stories to other groups that police come in contact with. An obvious theme of storytelling regarded criminals. These stories were 
regularly about students' newly gained insights into criminal life, such as codes of silence, brutality between criminals or gang-related practices. A number of stories also revolved around students' feeling sorry for criminals. Examples of this theme were often about exploitation amongst criminals, such as stories of individuals who had been robbed and/or beaten/stabbed/shot or about tragic life destinies, such as young offenders who had fallen victim to drugs. Finally, a number of stories about criminals also featured incongruities and contradictions between expectations and realities. A commonly occurring example of such incongruities featured criminals - "bad guys"-who were nice and/or sociable:

Recruit A tells a story about a thief he had apprehended. The thief had been caught red-handed whilst stealing from a store, and the recruit detained him. However, in their interactions, the offender was really nice, accommodating and humorous. A says that it was a pleasant experience to be around this guy and almost felt that it was a shame to 'bust' such a sympathetic person. This was something that was at odds with how he had pictured this type of work. A says that the episode made him think about the hardships of being fully objective in all situations as a police officer. He thought about how it might be challenging to respond to all equally even though one may feel very differently towards those individuals one apprehends, either in positive or negative aspects.

These types of incongruities were a common theme not only in relation to criminals. A reverse example of inconsistent behaviour was when "good guys" such as colleagues behaved in a blameworthy way. Whilst police and criminals expectedly were at the focal point in stories, there were also stories about mentally ill people and stories about members of the general public. Mentally ill individuals often appeared in stories either as doing harm to themselves (for instance, threatening suicide) or in cases of order disturbance. Members of the general public were often discussed in terms of bystanders, victims of crime or as visitors to bars and nightclubs.

Regarding stories and extreme situations, work experiences that demonstrated something out of the usual were frequently subjects for narration. For instance, stories exemplified a number of incidents of death that students encountered in their service, either through natural causes, such as being called out when corpses were found, or suicide dispatch calls, such as being called out to incidents of so-called train-jumpers. Other examples of extreme storylines regarded blood, gore and misery, such as people self-harming (i.e., cutting oneself, swallowing razorblades) or being exposed to violence by others (aggravated assaults, stabbings, torture-like situations). The tendency of stories to gravitate towards the extreme is a finding that is in accord with earlier observations of police storytelling as being focused on war stories (see Van Maanen 1973). As Moskos (2009) concluded, selection from memory out of police practice may favour the extreme rather than the mundane, as extreme courses of events simply might be more memorable. In the observed sessions, these themes in storytelling tended to arouse interest and spark further discussions about similar experiences of other students. Extremeness was furthermore, by the instructors regularly acknowledged as potential but not commonplace feature of policing.

Students also told stories about policing as actionable, for instance, of 'blue-light' emergency driving, the excitement of foot chases, house searches, drug seizures, arrests and conducting interrogations. Work tasks such as these have been described as related to a popular image of policing as an action-oriented, fast-paced occupation (cf. Reiner 
2010), and such popular images were reinforced through peer storytelling. Whilst more-mundane realities of policing also occurred as themes, these were less common. When these themes were raised, the storytellers often expressed frustration over boredom and tedious work shifts as well as the normative message that these types of work tasks are not what policing ideally should be about. Examples of this category were stories about citizen complaints, report writing, shoplifters or patrolling of quiet neighbourhoods by car whilst waiting (and wanting) for something to happen.

\section{Knowledge Retention through Storytelling}

In addition to analysing the practices of storytelling and the manifest levels of stories, an important facet of narrative sensemaking through storytelling is how stories are collectively understood and what messages stories convey, as these factors are indicative of how stories function to establish meaning. The analysis of what messages, standpoints and underlying meanings the stories conveyed in practice indicated three overarching themes: belonging, contributing and emotion management.

Regarding belonging, a number of stories established how students were part of the police community rather than being external to it. One facet of occupational positioning was expressed merely through the capacity to tell stories. These types of stories were interpreted as a means to transfer the message that students had access to the 'frontlines' as well as the 'backstages' of policing and through such access also had the capability to 'tell it like it is' to peers and instructors. Through stories, students repeatedly casted themselves as subjects who were part of an occupational community, rather than as students undergoing education and experiencing work practice from an external viewpoint. This type of positioning of oneself as a professional practitioner was, for instance, showcased in storytelling when students expressed themselves normatively around occupation-specific issues such as frustration over reorganizations, understaffing or coordination between the police and other agencies. Similarly, students expressed frustration over priorities that the police set as an organization, as some work tasks such as dealing with shoplifters or petty crimes were thought to claim an unreasonable amount of time and effort from the police. The ability to express these types of value-laden opinions about how the police should organize and what the police should do with their time hinges on credibility that stems from occupational belonging. Other aspects of belonging in stories were about immersion in policing, where students expressed how they became part of a community or a fellowship and they felt camaraderie. Such a story was told by a male student (M) who had spent his work placement period in one of Sweden's most crime-ridden districts, where gang problems were a major issue for the police.

M says he had been working with district police who had embraced "hot spots hot times" policing, which means they concentrated their efforts on places and times where things were 'going down'. M says that it was a really hard climate, and they experienced a lot of 'hairy situations' policing the district. One example of such a situation was when $\mathrm{M}$ had been off duty at a local grocery store in proximity to the district and neighbourhoods he had been policing. At the store, some gangaffiliated individuals identified him as a policeman and started shouting at him, upon which he quickly withdrew and left the place. M says that the situation was unpleasant because he was not on duty. However, when he told this to his 
colleagues at the district, they gave him exemplary support and arranged so that he got daily rides home from the district for the remaining time of the field training so he did not have to use public transport in the area and risk being recognized while off duty.

This story, on a manifest level, exemplifies police work practice and the realities of working in a tough neighbourhood and in a frightening situation. However, the key message of the story was rather the aspect of being recognized as a policeman by the ones policed (gang members) and, more significantly, by colleagues and the law enforcement community, who acted in support and defence of a novice officer.

Similar to stories that expressed how students were part of the police, a number of stories also indirectly exemplified how students were able to contribute to successful outcomes of the situations they faced in work practice. These types of stories could showcase how working methods proposed or suggested by students had successful outcomes. Other examples included when students could contribute to policing with "new" fresh knowledge, outlooks or perspectives that helped more experienced police practitioners in their work duties. These types of stories often exemplified the duplicitous nature of storytelling, as on a manifest level, they could be about serious crime, whilst on a latent level, they could be about the empowering feeling of being a novice police officer who was able to contribute to results in police practice.

A final tendency of stories on a latent level regarded emotion management, such as students dealing with fears, fright or, conversely, humorous episodes. A number of stories of action-filled or extreme policing, for instance, contained issues of being afraid and being worried as an important ingredient that amplified the seriousness of the situations. Likewise, in stories about how they had to intervene in situations involving bloodshed, students often expressed feelings of exposure as well as risk and fright of being infected by contagious blood (specifically hepatitis $\mathrm{C}$ or HIV viruses). They also told stories of injustice that often involved feelings of frustration and resignation. In contrast to the negative feelings, a number of stories also involved humorous elements, such as comic situations, in which students had to restrain from laughing in order not to embarrass colleagues or the involved individuals they were intervening against. Whilst these emotional reactions are opposed, a common denominator is the importance of managing one's emotions when being faced with work tasks.

Thus, storytelling practices supported students in regards to the question of how one should ideally feel about encountered phenomena and how one should handle, overcome or contain certain feelings. As a way to manage, manoeuvre around and process fear, fright, frustration or joy and personal feelings such as those of belonging, narrative sensemaking through storytelling seemed to entail a practice of emotion management. Through stories that elucidated and actualized emotions, students could validate their reactions in the face of peers and the instructor. Not at least, the instructor had an important role to aid students in their framing of stories. In this way, students' interpretation were often mirrored by how the instructor related to the content of stories or the implicit or explicit messages of stories. For instance, if the instructor showcased emotional distancing, this could be a cue that such distancing entails a facet of the professional ethos of the police. 


\section{Discussion}

In accordance with other research on knowledge integration, our findings show that opportunities for students to collectively share and articulate personal vocational experience is an important resource for learning and sensemaking in vocational education (Aarkrog 2005; Bijlsma et al. 2016). Billett (2009), for instance, discuss the importance of incorporating opportunities for students to share experiences after practicums into the formal curriculum of educational programmes. What the current study adds to the research on knowledge integration is a close examination of how storytelling practices afford narrative sensemaking of occupational experience. The findings indicate that the enactment of storytelling is highly performative, social and collective where stories are co-constructed and facilitated by peers, thus making individual experiential knowledge available for others to draw on. From a selection perspective, stories draw together meaning and exemplify events and experiences (Weick 1995), and our findings indicate that a common feature of stories was that actionable aspects of policing were emphasised and amplified in students' storytelling, while mundane work situations were downplayed. From a retention perspective, the findings indicated how stories established meaning regarding how students made sense of a professional ethos of police officers, how students identified themselves as part of the occupational community and how students could contribute to that community.

With these findings, we conclude that practices of storytelling that follow practicums, placements or other types of work-based experiences hold the potential to prompt and facilitate individuals' (both self and others) understandings of vocational knowledge. In short, stories function as 'sense-giving' (Gioia and Chittipeddi 1991), as they afford students interpretations about areas of occupational knowledge that otherwise might be difficult to address and teach in an academic setting. In this way, stories support the way students take on insider roles and their becoming practitioners, as stories increase knowledge of how to function in an occupational community (see Lave and Wenger 1991). These conclusions point to the positive potential of using storytelling as a knowledge-integrating practice and a tool for sensemaking of work-based experiences. Within policing specifically, the incorporation of storytelling activities into curricula holds potential to support peer learning and address forms of knowledge that are underemphasised under a currently dominant teacher-centred training paradigm of police education (see Birzer 2003; Moskos 2009).

Our findings also highlight challenges associated with storytelling practices in educational settings. One such challenge is the risk that storytelling of practice-based experiences may become skewed and geared towards sustaining and affirming almost mythological accounts of work practice through the circulation of war stories (Waddington 1999). In the following, we elaborate on the probable causes of this tendency, the potential negative consequences of war stories and how skewness can be counteracted.

\section{The Preference for "War Stories"}

As demonstrated in the findings, students' storytelling favoured extremeness and action orientation. Stories regularly drew on and reinforced established, dominant and popular beliefs about the police occupation as fast-paced, exciting, and focused on crime- 
fighting, life-and-death situations and violence. This empirical finding is in accord with a number of classic as well as contemporary studies of policing that have shown how war stories are common within the occupational police community but also deviate considerably from the realities of day-to-day police work, which is more clerical in nature (Van Hulst 2013; Waddington 1999; Courpasson and Monties 2017; McNulty 1994). This brings about the question of what role extremeness and action orientation play in narrative sensemaking of practice-based experiences. From a sensemaking perspective, an emphasis on the extreme in student storytelling can be seen as a consequence of how sensemaking processes unfold: Sensemaking entails a retrospective process that builds on selection out of experience (Weick 1995), and because of this, critical events become essential as affordances for how selection out of experience is formed. For this reason, war stories can be interpreted as having an appeal and a 'pedagogical power' that goes beyond discussions of the mundane aspects of work. Previously, research has highlighted this potential in terms of how war stories transfer experiential knowledge from the more experienced to newcomers (Ford 2003; Smith et al. 2014). Research has also shown how stories can function as a coping mechanism for police officers, as war stories can reinforce self-esteem and provide meaning to problematic occupational experiences (Waddington 1999). What our study adds to these findings is that police students also make use of storytelling for identification and self-enhancement purposes and that war stories emphasising action and excitement seem to be a driving force for early attachment to policing, as these accounts offer images students can identify with. With a pedagogical power, the question of what consequences ideational attachment through war stories may have for students also has to be raised. Previous research has highlighted how war stories can promote simplified, outdated and biased views of policing (Fletcher 1996; Van Hulst 2013). If students excessively base their expectations of future working conditions on such accounts, the result could be unrealistic expectations and so-called 'reality shocks' (Alain and Grégoire 2008) upon transferring from education to work. War stories may also contradict sanctioned and legitimate procedures and thus contribute to the undermining of formal curricula. This has been discussed as problematic, as it can lead to "training decay" (Chan $2001 \mathrm{p} \mathrm{116)}$ or even subcultural support for illegitimate or unjust occupational practices (Chappell and Lanza-kaduce 2009). Taken together, these notions indicate that while storytelling has the potential to drive students' sensemaking of work experience, it can also contribute to misalignment between expectations and formal curricula as well as with the realities of everyday police occupational practice. To fully make use of storytelling as a pedagogic activity, direction might be needed so that practice-based experience can be linked with reflective and critical perspectives on practice.

\section{Balancing Storytelling}

Storytelling as it was evidenced in this study was characterized by plurivocity, collectiveness and open-ended discussions amongst peers. While these features support trust as well as sharing and "drawing out" of authentic experience (see Billett 2009 p. 839 ), these characteristics in the local space of storytelling seem to be less effective in gearing discussions towards knowledge integration and the generation of reflection on practice. Arguably, storytelling practices characterized by 'connectivity' (Sappa and 
Aprea 2014) and balance between the sharing of work-based experiences and reflection upon such experiences holds potential to aid students in developing critical perspectives on occupational knowledge (Billett 2009; Billett 2014). To support this balance, the instructor or facilitator becomes of key importance: On the one hand, the instructor has a part in the establishment of a local space that encourages conversations and articulation of experience. On the other hand, the instructor has a role in prompting and guiding reflection and discussions on pressing issues related to experience (Bijlsma et al. 2016; Burchell and Dyson 2005). Our findings exemplify how the role of the facilitator is diverse. In regards of enactment of storytelling, the facilitator had a key role in triggering stories, mainly through probing questions and prompts for students to take the space with their stories. Furthermore, our findings also highlight how the facilitator had an important role in providing framing for students in regards of how to identify and retain messages of stories. For example, our findings regarding knowledge retention indicate how, students were attentive to how the facilitator reacted to stories and our interpretation of this finding was that the facilitator's reactions would be important cues for how to react as a member of the occupational community. While these examples highlight how facilitators engaged in storytelling practices, what was less obvious in our findings was the role of the facilitator in closing down discussions or actively directing these towards certain interpretations or knowledge domains. This lack of formalisation can on the one hand be argued to support psychological safety and reflection, as previous research has shown how high degrees of formalisation tend to collapse reflective conversations into rule following (Boud and Walker 1998). However, our study shows is how open-ended, self-initiated storytelling also can bring about problems, such as a bias for "war stories" and lack of depth.

With this as a basis, a question for further study is how balanced conversational climates can be facilitated and enacted and what role instructors with vocational experience can play in promoting this balance. Another opportunity for further research is to investigate the equivalents of police war stories in other vocational and professional educational programmes and contexts. Given that war stories have been studied in diverse work contexts (Orr 1990; Weick and Roberts 1993) and that war stories are effective in organizing know-how and experiential knowledge, further research on this issue could provide insights into how students position themselves in relation to their future occupational communities.

Acknowledgments This work was supported by a grant from the Swedish Research Council for Health, Working Life and Welfare [grant number 2014-1980].

Open Access This article is distributed under the terms of the Creative Commons Attribution 4.0 International License (http://creativecommons.org/licenses/by/4.0/), which permits unrestricted use, distribution, and reproduction in any medium, provided you give appropriate credit to the original author(s) and the source, provide a link to the Creative Commons license, and indicate if changes were made.

\section{References}

Aarkrog, V. (2005). Learning in the workplace and the significance of school-based education: A study of learning in a Danish vocational education and training programme. International Journal of Lifelong Education, 24(2), 137-147. doi:10.1080/02601370500056268.

Alain, M., \& Grégoire, M. (2008). Can ethics survive the shock of the job? Quebec's police recruits confront reality. Policing and Society, 18(2), 169-189. doi:10.1080/10439460802008702. 
Avby, G. (2015). Professional practice as processes of muddling through: A study of learning and sense making in social work. Vocations and Learning, 8, 95-113. doi:10.1007/s12186-014-9123-y.

Bijlsma, N., Schaap, H., \& de Bruijn, E. (2016). Students' meaning-making and sense-making of vocational knowledge in Dutch senior secondary vocational education. Journal of Vocational Education and Training, 68(3), 378-394. doi:10.1080/13636820.2016.1213763.

Billett, S. (2009). Realising the educational worth of integrating work experiences in higher education. Studies in Higher Education, 34, 827-843. doi:10.1080/03075070802706561.

Billett, S. (2014). Integrating learning experiences across tertiary education and practice settings: A sociopersonal account. Educational Research Review, 12, 1-13. doi:10.1016/j.edurev.2014.01.002.

Billett, S., Sweet, L., \& Glover, P. (2013). The curriculum and pedagogic properties of practice-based experiences: The case of midwifery students. Vocations and Learning, 6(2), 237-257. doi:10.1007/s12186-012-9094-9.

Birzer, M. L. (2003). The theory of andragogy applied to police training. Policing: An International Journal of Police Strategies and Management, 26(1), 29-42. doi:10.1108/13639510310460288.

Boje, D. (1995). Stories of the storytelling organization: A postmodern analysis of Disney as Tamara-land. Academy of Management Journal, 38(4), 997-1035.

Boud, D., \& Walker, D. (1998). Promoting reflection in professional courses: The challenge of context. Studies in Higher Education, 23(2), 191-206. doi:10.1080/03075079812331380384.

Boud, D., Rooney, D., \& Solomon, N. (2009). Talking up learning at work: Cautionary tales in co-opting everyday learning. International Journal of Lifelong Education, 28(3), 323-334. doi:10.1080 /02601370902799077.

Brown, A. D., Stacey, P., \& Nandhakumar, J. (2008). Making sense of sensemaking narratives. Human Relations, 61(8), 1035-1062. doi:10.1177/0018726708094858.

Brown, A. D., Colville, I., \& Pye, A. (2015). Making sense of sensemaking in organization studies. Organization Studies, 36(2), 265-277. doi:10.1177/0-170840614559259.

Burchell, H., \& Dyson, J. (2005). Action research in higher education: Exploring ways of creating and holding the space for reflection. Educational Action Research, 13(2), 291-300. doi:10.1080/09650790500200280.

Carmel, S. (2011). Social access in the workplace: Are ethnographers' gossips? Work. Employment and Society, 25(3), 551-560. doi:10.1177/0950017011407969.

Chan, J. (2001). Negotiating the field: New observations on the making of police officers. Australian and New-Zealand Journal of Criminology, 34(2), 114-133.

Chappell, A. T., \& Lanza-kaduce, L. (2009). Police academy socialization: Understanding the lessons learned in a paramilitary-bureaucratic organization. Journal of Contemporary Ethnography, 39(2), 187-214. doi:10.1177/0891241609342230.

Clandinin, D. J., \& Connelly, F. M. (2000). Narrative inquiry: Experience in story in qualitative research. San Francisco: Jossey-Bass.

Connelly, F. M., \& Clandinin, D. J. (1990). Stories of experience and narrative inquiry. Educational Researcher, 19(5), 2-14. doi:10.3102/0013189X019005002.

Conti, N. (2011). Weak links and warrior hearts: A framework for judging self and others in police training. Police Practice and Research, 12(5), 410-423.

Courpasson, D., \& Monties, V. (2017). "I am my body". Physical selves of police officers in a changing institution. Journal of Management Studies, 54(1), 32-57. doi:10.1111/joms.12221.

Dewey, J. (1985). The middle works, 1899-1924. Vol 10, essays on philosophy and education: 1916-1917. Carbondale: Southern Illinois University Press.

Fletcher, C. (1996). "The 250lb man in an alley": Police storytelling. Journal of Organizational Change Management, 9, 36-42. doi:10.1108/09534819610128788.

Ford, R. E. (2003). Saying one thing, meaning another: The role of parables in police training. Police Quarterly, 6(1), 84-110. doi:10.1177/1098611102250903.

Gioia, D. A., \& Chittipeddi, K. (1991). Sensemaking and sensegiving in strategic change initiation. Strategic Management Journal, 12(6), 433-448. doi:10.1002/smj.4250120604.

Hammersley, M., \& Atkinson, P. (2007). Ethnography: Principles in practice (3rd ed.). Milton Park: Routledge.

Lave, J., \& Wenger, E. (1991). Situated learning: Legitimate peripheral participation. Cambridge: Cambridge University Press.

Lawrence, T. B., \& Maitlis, S. (2007). Triggers and enablers of sensegiving in organizations. The Academy of Management, 50(1), 57-84.

Lincoln, Y. S., \& Guba, E. G. (1985). Naturalistic inquiry. Beverly Hills: Sage.

Maclean, M., Harvey, C., \& Chia, R. (2011). Sensemaking and storytelling in the recounting of elite business careers. Human Relations, 65(1), 17-40. doi:10.1177/0018726711425616.

Maitlis, S., \& Christianson, M. (2014). Sensemaking in organizations: Taking stock and moving forward. The Academy of Management Annals, 8(1), 57-125. doi:10.1080/19416520.2014.873177. 
McNulty, E. W. (1994). Generating common sense knowledge among police officers. Symbolic Interaction, $17(3), 281-294$.

Miles, M. B., Huberman, A. M., \& Saldaña, J. (2014). Qualitative data analysis a methods sourcebook (3rd ed.). Los Angeles: Sage.

Moskos, P. (2009). Cop in the hood-My year policing Baltimore's eastern district. Princeton: Princeton University Press.

Orr, J. E. (1990). Sharing knowledge, celebrating identity: War stories and community memory in a service culture. In D. S. Middleton \& D. Edwards (Eds.), Collective remembering: Memory in society (pp. 169189). Beverley Hills: Sage.

Punch, M. (1986). Politics and ethics of fieldwork. London: Sage.

Rantatalo, O., \& Karp, S. (2016). Collective reflection in practice: An ethnographic study of Swedish police training. Reflective Practice, 17(6), 708-723. doi:10.1080/14623943.2016.1206881.

Reiner, R. (2010). The politics of the police. Oxford University Press.

Sappa, V., \& Aprea, C. (2014). Conceptions of connectivity: How Swiss teachers, trainers and apprentices perceive vocational learning and teaching across different learning sites. Vocations and Learning, 7(3), 263-287. doi:10.1007/s12186-014-9115-y.

Shearing, C. D., \& Ericson, R. V. (1991). Culture as figurative action. The British Journal of Sociology, 42(4), 481-506.

Smith, R., Pedersen, S., \& Burnett, S. (2014). Towards an organizational folklore of policing: The storied nature of policing and the police use of storytelling. Folklore, 125(2), 218-237. doi:10.1080/0015587 X.2014.913853.

SOU. (2016). Polis i framtiden - polisutbildningen som högskoleutbildning. [a police for the future-police education as a higher education]. Stockholm: Fritzes.

Stenström, M., \& Tynjälä, P. (Eds.). (2009). Towards integration of work and learning. Strategies for connectivity and transformation. Amsterdam: Springer.

Torrance, H. (2012). Triangulation, respondent validation, and Democractic participation in mixed methods research. Journal of Mixed Methods Research, 6(2), 111-123.

Tynjälä, P. (2008). Perspectives into learning at the workplace. Educational Research Review, 3(2), 130-154. doi:10.1016/j.edurev.2007.12.001.

Tynjälä, P. (2013). Toward a 3-P model of workplace learning: A literature review. Vocations and Learning, 6 , 11-36. doi:10.1007/s12186-012-9091-z.

Tyson, R. (2016). The didactics of vocational Bildung: How stories matter in VET research. Journal of Vocational Education and Training, 68(3), 359-377. doi:10.1080/13636820.2016.1213762.

Van Hulst, M. (2013). Storytelling at the police station. British Journal of Criminology, 53(4), 624-642. doi:10.1093/bjc/azt014.

Van Maanen, J. (1973). Observations on the making of policemen. Human Organization, 32(4), 407-418.

Van Maanen, J. (1975). Police socialization: A longitudinal examination of job attitudes in an urban police department. Administrative Science Quarterly, 20(2), 207-228.

Waddington, P. A. J. (1999). Police (canteen) sub-culture. An appreciation. British Journal of Criminology, 39(2), 287-309. doi:10.1093/bjc/39.2.287.

Walmsley, A., Thomas, R., \& Jameson, S. (2006). Surprise and sense making: Undergraduate placement experiences in SMEs. Education and Training, 48(5), 360-372. doi:10.1108/00400910610677063.

Weick, K. E. (1995). Sensemaking in organizations. Thousand Oaks: Sage.

Weick, K. E., \& Roberts, K. H. (1993). Collective mind in organizations: Heedful interrelating on flight decks. Administrative Science Quarterly, 38(3), 357. doi:10.2307/2393372.

Weick, K. E., Sutcliffe, K., \& Obstfeld, D. (2005). Organizing and the process of sensemaking. Organization Science, 16(4), 409-421. doi:10.1287/orsc.1050.0133.

Worth, S. E. (2008). Storytelling and narrative knowing: An examination of the epistemic benefits of well-told stories. The Journal of Aesthetic Education, 42(3), 42-56. doi:10.1353/jae.0.0014.

Oscar Rantatalo , PhD, is a lecturer at the Centre for Police Education at Umeå University, Sweden. His research interests include areas such as workplace learning, education-work transitions, organizational sensemaking, and policing.

Staffan Karp , $\mathrm{PhD}$, is an associate professor in Pedagogy in the Department of Education at Umeå University in Sweden. His main research interests are learning processes in police education and police practice in relation to societal change. 